\title{
NEW SPECIES OF AFRICAN CHRYSIS (HYMENOPTERA: CHRYSIDIDAE)*
}

\author{
BY RICHARD M. BOHART \\ Department of Entomology, University of California, \\ Davis, CA 95616
}

In the past few years I have examined several thousand Chrysidini from Africa in connection with a generic revision. The bulk of this material came from museums and private collectors. In addition I personally collected some specimens in Kenya and South Africa. Most of the original types of African species have been studied.

Commonly collected species of Afrotropical Chrysis which have broad distributions are lincea Fabricius, stilboides Spinola, mediocris Dahlbom, antennata Mocsáry, dira Mocsáry, angolensis Radoszkowski, aurifascia Brullé, and mionii Guérin. All of these were described more than 75 years ago, some much longer. Nearly 150 additional species of Chrysis (plus synonyms) are known to occur in the Region, although they are less commonly taken. Most of these were named by A. Mocsáry, R. du Buysson, and E. Edney. The use of Malaise traps by F. W. Gess, C. M. Eardley, and others in the past 15 years has increased the catch of previously "rare" species, and also the proportion of males. Based on the Chrysis I have seen, the list of Afrotropical species in this genus should easily reach 250 .

Some of the more distinctive unnamed forms are described below with indication of collectors and museum repositories. Abbreviations used in the descriptions are: F-I etc., flagellomeres; TFC, transverse frontal carina; MOD, median ocellus diameter; T-I etc., terga; S-I etc., sterna.

Museum repositories are identified by the cities in which they are located.

BUDAPEST, Hungarian National Mus.; CAMBRIDGE, Mus. of Comparative Zoology, Massachusetts; CAPE TOWN, South African Mus.; COPENHAGEN, Zoological Mus., Denmark; DAVIS, University of California Bohart Museum.; GAINESVILLE-AI,

Manuscript received by the editor July 1, 1987. 
American Entomological Institute, Florida; GAINESVILLE-FS, Florida State Collection of Arthropods; GENOA, Natural History Mus., Italy; GRAHAMSTOWN, Albany Mus., South Africa; LUND, University Mus., Sweden; PRETORIA-NC, National Collection of Insects, South Africa; PRETORIA-TM, Transvaal Mus., South Africa; TERVUREN, Congo Mus., Belgium.

\section{Chrysis aspredinis Bohart, new species}

HOLOTYPE MALE: Length $7 \mathrm{~mm}$. Body rather robust, green, becoming blue and purplish blue, F-I green in front, wings lightly stained. Punctation coarse and close, a little finer on vertex and T-II-III but close. F-I $2.8 \times$ as long as broad; face unusually broad, scapal basin punctate in outer one-third, microridged and depressed in middle one-third; TFC distinct, biconvex (Fig. 1); malar space 1.5 MOD; subantennal space 1 MOD. Pronotum shorter than scutellum, median groove weak; metanotum rounded; mesopleuron edentate, episternal and scrobal sulci distinct, latter broad; propodeal projection slender, sharp, incurved behind. Midline of T-II a little raised. T-III slightly saddled, a small median prepit depression, lateral margin concave except for a large rounded hump in basal onefourth; pit row deep, pits distinct, 4 sharp but short distal teeth grouped inside lateral margins (Fig. 1); S-II spots large, nearly touching, occupying about one-half of sternum.

FEMALE: About as in male. Length $8 \mathrm{~mm} ; \mathrm{F}-\mathrm{I} 3.2 \times$ as long as broad, scapal basin with coarse lateral punctures.

Male holotype, (PRETORIA-TM), SOUTH AFRICA: Cape Prov., van Rhynsdorp, VII-VIII-1927 (G. van Son). Paratype male, same data as holotype (DAVIS).

DISCUSSION: The odd shape of the short T-III which is broad with distal teeth well inside the lateral margin (Fig. 1), the median prepit depression, basolateral hump, and unusually coarse punctation are features of the splendens group. Other species besides aspredinis are dentipleuralis (Brauns), munita Buysson, splendens Dahlbom, and vansoni (Brauns). From all of these, aspredinis differs by its unmodified metanotum, simpler TFC, absence of a delimited midocellar area, and larger S-II spots. 

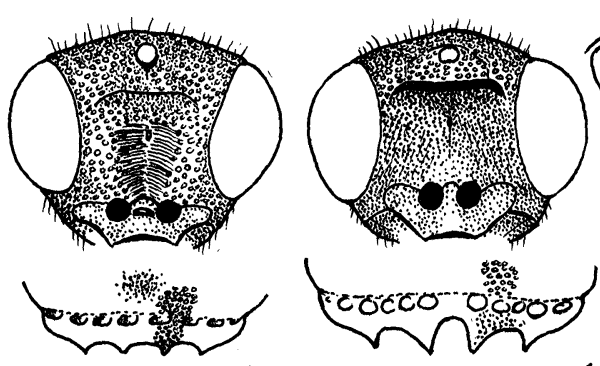

1. aspredinis $\widehat{\delta}$

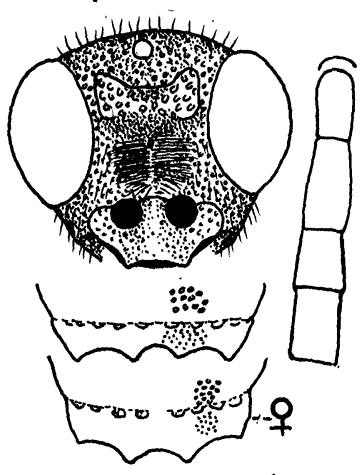

2. brothersi $\delta$
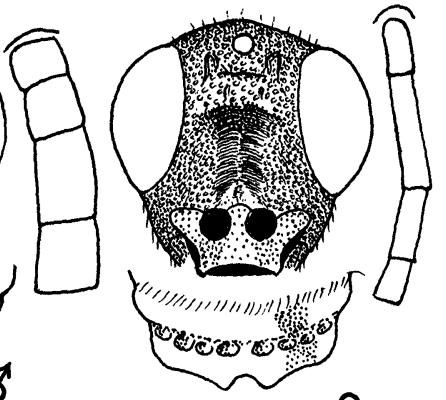

3. capana 우

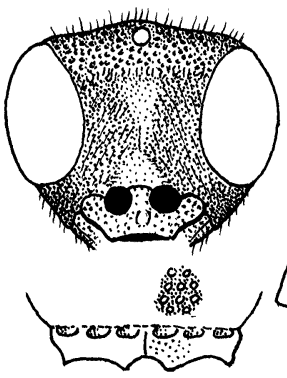

5. crenula $\overparen{\sigma}$

4. capicola $\widetilde{\sigma}$
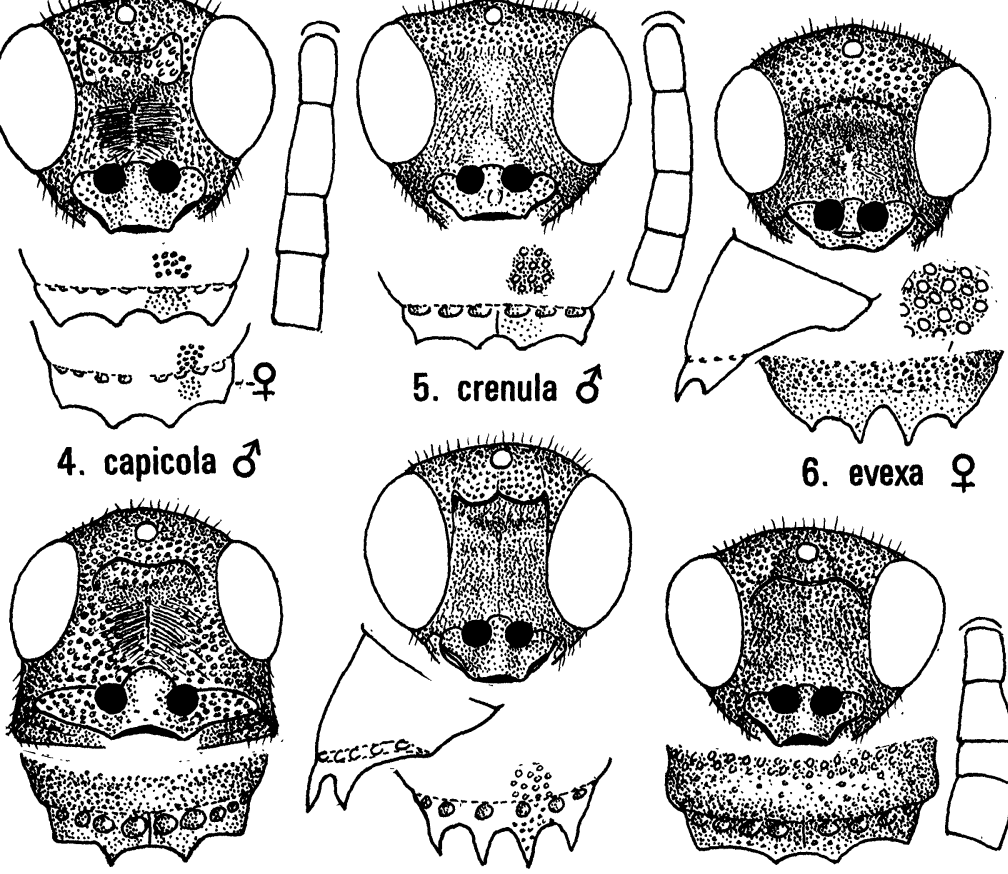

6. evexa 우

7. genosa $q$

8. kenyana $q$

9. krugerana $\sigma^{\pi}$

Figs. 1, 7, face and apex of T-III; 2, 3, 4, 5, 9, also pedicel to T-III of antenna (enlarged). Figs. 6, 8, face, T-III lateral and apex dorsal. 
Chrysis brothersi Bohart, new species

HOLOTYPE MALE: Length $7 \mathrm{~mm}$. Body robust, blue to bluish purple, ocellar area and broad median stripe on mesonotum purple; tarsi reddish brown, F-I blue in front, wings weakly stained. Punctation medium coarse, somewhat spaced on T-II-III. F-I as broad as long (Fig. 2), a little longer than pedicel, three-fifths as long as F-II; scapal basin punctate, dense silvery hair in outer two-fifths; TFC strong, midocellar area margins arising from sublateral angles; midocellus lidded; malar space 1.3 MOD; subantennal space 1.6 MOD. Pronotum shorter than scutellum, median groove well developed; metanotum rounded; mesopleuron bidentate, episternal and scrobal sulci distinct; propodeal projection pointed, very lightly convex behind. Midline of T-II weakly indicated; T-III rounded before moderately deep pit row, prepit bulge hardly raised, lateral margin sinuate, 4 sharp and acute distal teeth well within lateral margin, median emargination deep (Fig. 2), submedian one more shallow; S-II spots medium, round, narrowly separated.

FEMALE: About as in male. Length $7.5 \mathrm{~mm}$. More green than blue, F-I $1.8 \times$ as long as broad, about as long as F-II, T-III a little saddled, distal teeth evenly spaced.

Male holotype (GRAHAMSTOWN) SOUTH AFRICA: Cape Prov., $30 \mathrm{~km}$ se, Hoedspruit, XI-14-78 (D. J. Brothers, C. F. J. Guillarmod). Paratypes, female, SOUTH AFRICA: Transvaal Prov.: Langjan Nature Reserve, I-24-82 (C. D. Eardley, PRETORIA-NC); female, Mogol Nature Reserve, XI-23-79 (S. J. van Tonder and G. L. Princeloo, DAVIS).

DISCUSSION: The short male F-I (Fig. 2), rounded metanotum, T-III teeth inside an expansion, and medium-sized round S-II spots narrowly separated, all place brothersi near zuluana Mocsáry. The latter differs by the much finer punctation and extensive microsculpture.

The species is named for a collector of the holotype, the wellknown hymenopterist, Dennis Brothers.

\section{Chrysis capana Bohart, new species}

HOLOTYPE FEMALE: Length $7 \mathrm{~mm}$. Body slender, green, F-I mostly green in front, wings lightly stained. Punctation moderate and close on vertex and notum, somewhat spaced on T-I, finer and a little 
spaced on T-II, fine and close on T-III. F-I $4.3 \times$ as long as broad, $2.1 \times$ as long as pedicel; scapal basin punctate on outer one-third, microridged on middle third; TFC partly broken, M-like (Fig. 3); malar space 2.8 MOD; subantennal space 1.8 MOD. Pronotum as long as scutellum, grooved in front; metanotum rounded, mesopleuron edentate, episternal and scrobal sulci moderately impressed; propodeal projection pointed, concave behind. Midline of T-II faint in anterior one-half; T-III saddled before low transverse prepit swelling, lateral margin a little convex, pit row well developed, distal margin notched medially between rounded teeth (Fig. 3), apicolateral corners broadly rounded; S-II spots long oval, widely separated.

Female holotype (PRETORIA-TM), SOUTH AFRICA: Cape Prov., Willowmore (Dr. Brauns). Paratypes, 3 females, same data as holotype (PRETORIA-TM, DAVIS).

DISCUSSION: This is related to exsecata Mocsáry on the basis of its laterally rounded and medially notched distal rim of T-III, M-like TFC, slender F-I, and medially microridged scapal basin. However, capana is a larger and more slender species, S-II spots much farther apart, TFC partial, F-I 4.3 rather than $3 \times$ as long as broad, and T-III finely rather than coarsely punctate (Fig. 3).

\section{Chrysis capicola Bohart, new species}

HOLOTYPE MALE: Length $6 \mathrm{~mm}$. Body moderately slender, green, grading to purple in ocellar area, T-II medially, and T-III; F-I weakly green, wings lightly stained. Punctation moderate and close. F-I $2 \times$ as long as broad, F-II $1.2 \times$ and a little shorter than F-III which is $1.5 \times$ as long as broad (Fig. 4); scapal basin punctate in outer one-fourth, microridged with some punctures in middle half; TFC like a broad and rounded M; malar space 2.3 MOD; subantennal space 1.6 MOD. Pronotum a little shorter than scutellum, median groove well developed; metanotum rounded; mesopleuron edentate, episternal and scrobal sulci well developed; propodeal projection sharp, incurved behind. Midline of T-II-III faint; T-III with a low medial prepit swelling, lateral margin nearly straight, pits distinct in a shallow pit row groove, postpit area short, 4 short and obtuse distal teeth (Fig. 4); S-II spots long oval, 4.5 MOD apart.

FEMALE: About as in male; F-I $2.4 \times$ as long as broad, longer than F-II which is longer than F-III; subantennal space 1.8 MOD; TFC rather faint; one female mostly purple; T-III (Fig. 4). 
Male holotype (GAINESVILLE-AI), SOUTH AFRICA: Cape Prov., Kirstenbosch, XI-25-70 (H. and M. Townes). Paratypes (SOUTH AFRICA, Cape Prov.), 5 males, some data as holotype (also DAVIS), 2 females, IX and I, Jonkersboek (H. and M. Townes, GAINESVILLE-AI; V. Whitehead, CAPE TOWN); female, Cape Nature Reserve, III-10-68 (P. Spangler, DAVIS).

DISCUSSION: The slightly short male F-II (Fig. 4) places this species in the splendidula-senegalensis group along with other African species: laeta Dahlbom, senegalensis Mocsáry, and impudens Edney. From all of these, capicola differs by its longer malar space (2.3 MOD vs. about 1.0). Also, T-III teeth are less sharp, and male F-III-X are dark. In the other 3 species these male articles tend to be reddish. In kenyana Bohart the malar space is 0.8 MOD and it has a distinctive pretegular hook.

Chrysis crenula Bohart, new species

HOLOTYPE MALE: Length $4.5 \mathrm{~mm}$. Body slender, blue-green with some purplish, especially at base of T-II and on T-III, wings water clear. Punctation moderately coarse, punctures 0.5-1.0 PD apart and intervening space micropunctate, especially on terga. F-I 2.1X as long as broad, a little longer than F-II, which is equal to F-III; scapal basin mostly punctate and silver pubescent, narrowly polished medially; brow rough but without a TFC (Fig. 5); malar space 2.5 MOD; subantennal space 1.5 MOD. Pronotum shorter than scutellum, median groove weak; metanotum rounded; mesopleuron edentate, episternal and scrobal sulci weak; propodeal projection slender and sharp, incurved behind. Midline of T-II faint; T-III evenly convex before well developed pit row, lateral margin straight, 4 short distal teeth, middle pair close together (Fig. 5); S-II spots oval, separated by 2 MOD.

FEMALE: about as in male, T-III slightly saddled.

Male holotype (PRETORIA-NC), SOUTH AFRICA: Transvaal Prov., Roodenplaat, XII-1978 (C. D. Eardley). Paratypes, 2 females, same data as holotype (PRETORIA-NC, DAVIS); female, Natal Prov., Umfolozi Game Reserve, XI-20-78 (D. J. Brothers, C. F. J. Guillarmod, GRAHAMSTOWN).

DISCUSSION: This small slender species, with T-III notched apically is a little like delicatula but the moderately long F-I and absence of a TFC (Fig. 5) rule it out of that group. In addition the interpunctural microsculpture is distinctive. 
Chrysis evexa Bohart, new species

HOLOTYPE FEMALE: Length $7 \mathrm{~mm}$. Body medium slender, green, a little purple in midscutal area, F-I weakly green, tarsi light brown, wings slightly stained. Punctation of head, notum and T-I moderate to coarse (on scutum), interspaces partly microsculptured; T-II-III with small, somewhat spaced punctures with intervening microsculpture. F-I $2 \times$ as long as broad; scapal basin with fine, striatiform punctation; brow rough and partly obscuring TFC which is parenthesis-like (Fig. 6); malar space 1.6 MOD; subantennal space 1.0 MOD. Pronotum shorter than scutellum, median groove shallow, lateral margin (in dorsal view) expanded before middle; metanotum with a short, posteromedian, spoonlike projection; mesopleuron edentate, episternal and scrobal sulci deep, leaving 2 polished areolae at bottom of mesopleural side; propodeal projection sharp, incurved behind. Midline of F-I-II faint; T-III hardly saddled, no prepit bulge, lateral margin slightly concave except for a flattened lobe in basal one-fifth (Fig. 6), pit row shallow but pits distinct, 4 sharp distal teeth (Fig. 6); S-II spots medium large, oval, practically touching.

Female holotype (CAMBRIDGE), ZAIRE: Katanga, Lubumbashi, XI-23-20 (J. Bequaert). Female paratype, same data as holotype (DAVIS).

DISCUSSION: This species belongs to the wahlbergi group, all of which have some sort of basolateral projection on T-III. C. evexa is close to hoplites Mocsáry but in evexa the shape of T-III (Fig. 6), shorter metanotal projection, evenly incurved propodeal projection, and generally more slender body are distinctive.

\section{Chrysis genosa Bohart, new species}

HOLOTYPE FEMALE: Length $7 \mathrm{~mm}$. Body slender, greenish-blue; purple on scutum medially, metanotum, T-II-III basolaterally; F-I-II blue in front; wings lightly stained. Punctation moderate and close on vertex and notum, a little spaced on T-II and on T-III prepit hump. F-I $2.6 \times$ as long as broad; scapal basin punctate in lateral two-fifths, microridged in middle one-fifth; TFC well developed, biconvex; face greatly widened at mandible base where it is nearly twice as broad as at TFC (Fig. 7); malar space 4 MOD; subantennal space 1.5 MOD; postocellar area unusually large. Pronotum about as long as scutellum, median groove present but 
weak; metanotum rounded; mesopleuron edentate, episternal and scrobal sulci moderately impressed; propodeal projection slender, sharp, incurved behind. T-I with subbasal humps unusually prominent; T-II midline faint; T-III slightly saddled, a median hump before pit row, lateral margin straight, pits deep, 4 distal teeth, lateral pair forming a right angle, middle pair closer together and sharp but short (Fig. 7); S-II spots long oval, 5 MOD apart.

Female holotype (PRETORIA-NC), SOUTH AFRICA: Transvaal Prov., Nylsvley Nature Reserve, XII-11-79 (W. A. Harrop). Paratype female, SOUTH AFRICA: Transvaal Prov., Entabeni Forest Reserve, Soutpansberg, XI-7-80 (M. W. Mansell, DAVIS).

DISCUSSION: The exceptionally broad face at the mandible base is distinctive for this medium-sized species (Fig. 7). This broadening also affects the interantennal and eye-genal carina spaces, which are greater than usual. The rather knobby T-I in front is reminiscent of the palearctic subsinuata group but the similarity is probably coincidental. In most respects genosa fits into the delicatula group, but discovery of the male will be needed to confirm this. Although mandibularis Buysson is considerably smaller, and its interpunctural areas are microsculptured, the laterally expanded face and other features are much like those of genosa.

\section{Chrysis kenyana Bohart, new species}

HOLOTYPE FEMALE: Length $6 \mathrm{~mm}$. Body slender, green marked with purple in ocellar areas, most of midscutal area, T-II sublateral basal spots, T-III basally and postpit. F-I green in front; wings nearly clear; tarsi brownish yellow. Punctation moderate and close, coarse toward middle of T-II. F-I $1.3 \times$ as long as broad, about as long as pedicel, a little longer than F-II; scapal basin with sides nearly parallel (Fig. 8), finely punctate and faintly microridged medially; TFC M-like; midocellar area partly margined; malar space 0.8 MOD; subantennal space 1.8 MOD. Pronotum as long as scutellum, a shallow median groove; scutum with a strong pretegular hook; metanotum rounded; mesopleuron edentate, episternal and scrobal sulci well developed; propodeal projection sharp, incurved behind. Midline of T-II a flat median welt; T-III slightly saddled, a low transverse prepit swelling, lateral margin with a distinct obtuse angle at middle point (Fig. 8), pit row moderately impressed, pits relatively large, distal margin with 4 long, sharp teeth (Fig. 8); S-II spots oval, 2.5 MOD apart. 
Female holotype (COPENHAGEN), KENYA: Tiwi Beach, IV19-76 (H. Gonget). Paratype female, same locality as holotype, IV14-76 (K. Gonget, DAVIS).

DISCUSSION: This species appears to be in the splendidulasenegalensis group, and is quite similar to laeta. However, the pretegular scutal hook of kenyana, as well as the prominent angle on the lateral T-III margin (Fig. 8) are distinctive.

Chrysis krugerana Bohart, new species

HOLOTYPE MALE: Length $8.5 \mathrm{~mm}$. Green with tinges of purple, T-III mostly purplish blue, F-I green in front, wings brown except toward apex. Punctation moderately coarse and close on vertex and notum, punctures of terga mostly $0.5 \mathrm{PD}$ apart. F-I as broad as long and slightly longer than pedicel, F-II shorter, F-III a little longer than F-I (Fig. 9); scapal basin with close and somewhat transversely striatiform punctation, sparsely pubescent on outer one-third; TFC strong, weakly and irregularly biconvex (Fig. 9); midocellar area slightly indicated; malar and subantennal spaces each 1.7 MOD. Pronotum a little shorter than scutellum, median groove weak; metanotum rounded; mesopleuron edentate, scrobal and episternal sulci strong; propodeal projection sharp, concave behind. T-II midline a faint welt; T-III with a prominent rounded prepit bulge, lateral margin nearly straight, pit row moderately impessed, weakly divided medially, 4 obtuse distal teeth (Fig. 9), S-II spots ovoid, 3 MOD apart.

FEMALE: About as in male; F-I-II green in front, F-I $2 X$ as long as broad; T-II purple basolaterally.

Male holotype (PRETORIA-NC), SOUTH AFRICA: Transvaal Prov., Kruger National Park, Pretoriuskop, I-17-85 (G. L. Princeloo). Paratypes (SOUTH AFRICA, Transvaal), male, female, Barberton, XI-11-78 (C. D. Eardley, G. L. Princeloo (PRETORIA-NC); male, Hectorspoint, XI-23-73 (A. Strydam, PRETORIA-TM); male, 2 females, Lapalala Nature Reserve, I-23-87 (R. B. Kimsey, DAVIS).

Discussion: The form of the male antenna (Fig. 9) place this in the cerastes group where it is the only known South African species of this color and moderate size. 


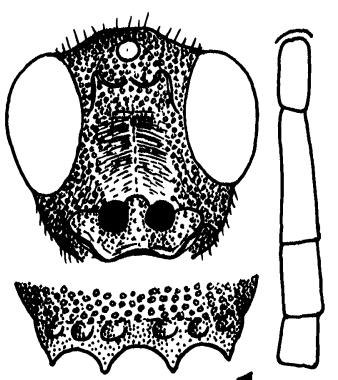

10. nambica $\sigma^{\top}$
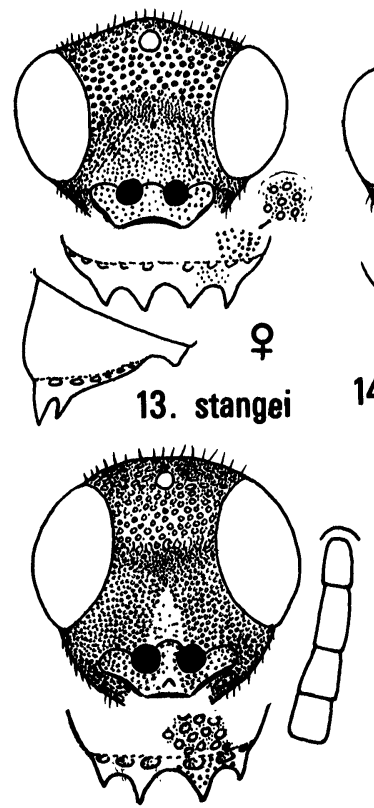

16. ugandae $ठ$

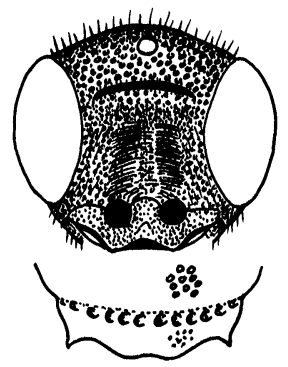

11. rhinata ?

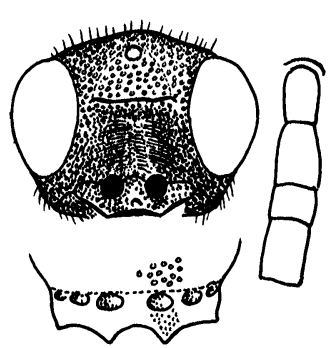

14. stevensoni' के

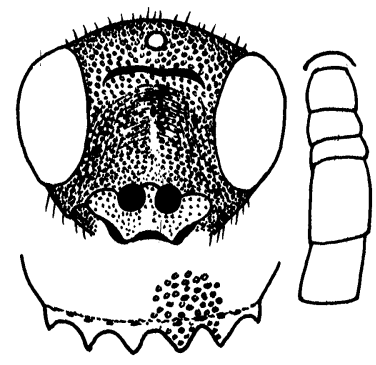

12. somaliae $\sigma^{\top}$

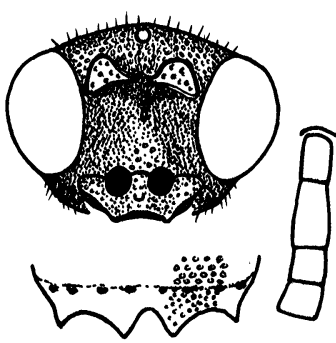

15. tesserops $\delta$

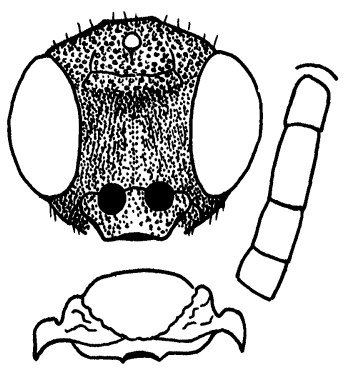

17. senegalana

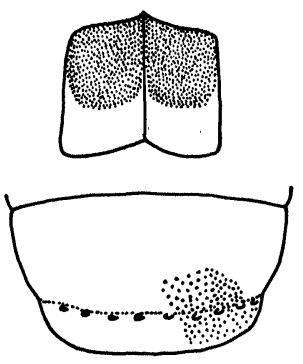

18. senegalana $\sigma^{\top 7}$

Fig. 11, face and apex of T-III; 10, 12, 14, 15, 16, 17, also pedicel to T-III of antenna (enlarged). Fig. 13, face, T-III lateral and apex dorsal. Fig. 18, S-II and T-III apex. 


\section{Chrysis namibica Bohart, new species}

HOLOTYPE MALE: Length $5 \mathrm{~mm}$. Body slender, blue-green with green and purple tinges, a laterobasal purple spot on T-II, F-I weakly green, wings clear. Punctation moderate and close. F-I 3.4X as long as broad (Fig. 10). Scapal basin punctate and silver haired on lateral one-third, polished and microridged in central one-third; TFC M-like (Fig. 10); midocellus lidded; malar space 2.2 MOD; subantennal space 1 MOD. Pronotum a little shorter than scutellum, median groove weak; metanotum rounded, mesopleuron edentate, mesopleural and scrobal sulci shallow; propodeal projection sharp, incurved behind. Midline of T-II a faint welt; T-III evenly convex before moderately deep and large pit row, lateral margin straight, 4 sharp but short distal teeth (Fig. 10); S-II spots large, quadrate, practically touching.

FEMALE: About as in male. T-III saddled, slightly bent out mediolaterally, S-II spots small, nearly touching.

Male holotype (DAVIS), NAMIBIA: Namib Desert Park, Gobabeb, II-12-74 (M. E. Irwin). Paratype female, same data as holotype (L. Lyneborg, COPENHAGEN).

DISCUSSION: The long F-I, clear wings, polished and microridged middle of the scapal basin (Fig. 10), and lidded midocellus are distinctive for this slender species. The species group appears to be comparata-scutellaris, but the long and slender F-I is atypical (Fig. 10).

\section{Chrysis rhinata Bohart, new species}

HOLOTYPE FEMALE: Length $5.5 \mathrm{~mm}$. Body moderately slender, greenish-blue with purple in ocellar area, midscutum and in sublateral basal spots on T-I-II; F-I-II green in front, wings lightly stained. Punctation moderately coarse and close. F-I $2.3 \times$ as long as broad; scapal basin punctate in outer two-fifths, microridged in middle one-fifth (Fig. 11); TFC a slightly irregular downcurved crescent; midocellus narrowly lidded; malar and subantennal space each about 1 MOD. Pronotum about as long as scutellum, median groove weak; metanotum rounded; mesopleuron edentate, scrobal and episternal sulci distinct; propodeal projection sharp, incurved behind. No midline on T-II; T-III nearly straight before pit row in 
lateral view, lateral margin slightly convex, pit row moderately deep, without a strong median division, distal margin with a pair of short but sharp lateral teeth, medial pair rounded and weakly divided, forming a broad nasiform projection (Fig. 11); S-II spots small, round, 1.5 MOD apart.

Female holotype (PRETORIA-NC), SOUTH AFRICA: Transvaal Prov., Kruger National Park, Pafuri, I-26-84 (C. D. Eardley). Paratype female, ZAIRE: Mulubulu (J. Bequaert, DAVIS); paratype female, NIGERIA: U-Ora Creek, XI-17-74 (J. T. Medler, DAVIS); paratype female, SOUTH AFRICA: Hluhlawe Game Reserve, XI-13-70 (H. and M. Townes, GAINESVILLE-AI).

DISCUSSION: The facial features, such as short malar and subantennal spaces, and crescentic TFC (Fig. 11) suggest that rhinata belongs in the maculicornis group. Discovery of the male will be needed for confirmation. The odd, nasiform look of the T-III apex is found elsewhere only in the bihamata group. However, in rhinata the scapal basin is microridged medially, and the subantennal space is shorter.

\section{Chrysis senegalana Bohart, new species}

HOLOTYPE MALE: Length $5 \mathrm{~mm}$. Body moderately stout, bluegreen, F-I dark, wings faintly stained. Punctation close, moderate on vertex and notum, small on terga, indistinct on T-III postpit. F-I $2 \times$ as long as broad (Fig. 17), lower frons nearly parallel-sided, quadrate, finely punctate and not crossridged; TFC a broad reverse U (Fig. 17), quite weak, strongest medially; malar space 0.6 MOD; subantennal space 2 MOD. Pronotum nearly as long as scutellum, hardly grooved; metanotum rounded, mesopleuron weakly bidentate below scrobal sulcus which is distinct and a little areolate, episternal sulcus linear; propodeal projection sharp, incurved behind (Fig. 17). Midline of T-II indistinct; T-III not saddled, lateral margin with a slight basal convexity; pit row sunken but well devloped, postpit area a prominent curved flange (Fig. 18); S-II spots large, quadrate, touching (Fig. 18).

FEMALE: About as in male.

Male holotype (LUND), SENEGAL: $3 \mathrm{~km} \mathrm{n}$. Tanaff, III-7-77 (Cederholm, Danielson, Larson). Paratypes, male, 7 females, same data as type (LUND, DAVIS, PRETORIA-TM). 
Discussion: The T-III distal flange is similar to that in some Spintharina, but the incurved propodeal projection (Fig. 17) rules out a close relationship. The weakly bidentate lower mesopleuron, quadrate lower frons, flanged T-III, and large S-II spots (Fig. 18) place senegalana in the cuprata group. It is the first species of the group recorded from the Afrotropical Region. The all green color, and large T-III postpit flange are distinctive.

\section{Chrysis somaliae Bohart, new species}

HOLOTYPE MALE: Length $7 \mathrm{~mm}$. Body moderately stout, green, some purple in ocellar area, midscutum, and basolaterally on T-I-II; pedicel and flagellum dark, tarsi reddish brown, wings lightly stained. Punctation moderate to coarse, slightly spaced on terga. F-I broader than long and shorter than pedicel, F-II even shorter, F-I-II together shorter than F-III (Fig. 12), scapal basin with outer onethird punctate, upper middle one-third weakly microridged between punctures; TFC strong, crescentic (Fig. 12); malar space 2.0 MOD; subantennal space 2.0 MOD. Pronotum shorter than scutellum, median groove present but weak; metanotum rounded; mesopleuron edentate, episternal and scrobal sulci distinct; propodeal projection sharp, incurved behind. T-II midline a raised welt; T-III evenly convex before pit row which is obsolete, lateral margin slightly sinuate, 6 short but sharp distal teeth (Fig. 12), outermost pair shortest; S-II spots rather small, round, 2 MOD apart.

Male holotype (DAVIS), SOMALIA: Laga, XI-29-1894 (A. D. Smith).

DISCUSSION: This species does not seem to be related to any other African Chrysis. Especially notable are the extremely short F-I-II which separates it from all other 6-toothed Chrysis (Fig. 12). A few other species in the smaragdula group, and all of the oculata group have F-I short, but none have this condition in both F-I and F-II.

\section{Chrysis stangei Bohart, new species}

HOLOTYPE FEMALE: Length $5.5 \mathrm{~mm}$. Body moderately stout, green, grading to blue on T-II-III, tegular purple, tarsi light brown, F-I green in front, wings nearly clear. Punctation moderately coarse and slightly spaced on vertex, notum, and T-I, interpunctural areas microsculptured; T-II-III punctures small, somewhat spaced, inter- 
spaces obviously microsculptured. F-I twice as long as broad, scapal basin punctate in outer one-third, weakly microridged in middle one-third; brow rough without indication of TFC (Fig. 13); malar space and subantennal space each about 1 MOD. Pronotum shorter than scutellum, median groove weak; metanotum with a posteromedian spoonlike projection extending about 1.5 MOD; mesopleuron edentate, episternal and scrobal sulci distinct, a large areole below latter; propodeal projection sharp, with a small convexity at middle of posterior edge. Midline of T-II indistinct; T-III evenly convex prepit, lateral margin concave except for a strong tooth in basal one-fifth (Fig. 13), pit row well impressed, pits large, 4 sharp distal teeth (Fig. 13); T-II spots long oval, close together, weakly pigmented (Fig. 13).

Female holotype (GAINESVILLE-FS) NAMIBIA: $68 \mathrm{~km}$ e. Karibib, II-4-83 (L. Stange, B. Miller). Paratype, female, ZAIRE: Urundi Kisenyi, May, 1955 (F. J. Francois, TERVUREN). Other paratypes (SOUTH AFRICA, Transvaal Prov.) female, Ellisras, XI-22-78 (D. J. Brothers, C. E. J. Guillarmod, GRAHAMSTOWN); female, Mogol Nature Reserve, XI-23-79 (S. J. van Tonder, PRETORIA-NC), female, Barberton, XI-11-78 (C. M. Eardley, PRETORIA-NC) female, Lapalala Nature Reserve, I-2389 (R. B. Kimsey, DAVIS).

DISCUSSION: A close relative in the wahlbergi group is hoplites Mocsáry. Distinguishing features of stangei are the small size (length $5.5 \mathrm{~mm}$ vs. 8.0), absence of the TFC, shorter malar space (1 MOD vs 1.3), more distinctly toothlike projection basolaterally on T-III (Fig. 13), deeper pit row, and differently shaped propodeal projection (hoplites is notched basoposteriorly). The species is named for a collector of the holotype, my friend Lionel Stange.

Chrysis stevensoni Bohart, new species

HOLOTYPE MALE: Length $5 \mathrm{~mm}$. Greenish blue, marked with purple in ocellar area, midscutum, T-II basolaterally, T-III basally; F-I green in front; wings nearly clear. Punctation moderate and close. F-I $1.3 \times$ as long as broad, as long as pedicel, longer than F-II, shorter than F-III (Fig. 14); scapal basin punctate and with silvery hair on lateral third, microridged otherwise; TFC nearly straight; malar space 1.8 MOD; subantennal space 1.2 MOD. Pronotum a little shorter than scutellum, hardly grooved medially; metanotum 
rounded; mesopleuron edentate, episternal sulcus strong, scrobal sulcus weak and incomplete; propodeal projection sharp, incurved behind. No T-II midline; T-III evenly convex before well-indented pitrow, lateral margin straight, 4 distal teeth of which outer pair are obtuse (Fig. 14), inner pair sharp but short; S-II spots oval, widely separated.

FEMALE: About as in male; F-I $2 \times$ as long as broad, F-I-II green in front; malar space 2 MOD.

Male holotype (GRAHAMSTOWN), SOUTH AFRICA: Cape Prov., Hilton, XI-9-75 (F. W. Gess). Paratypes, one male, 4 females, topotypical, X and XI (GRAHAMSTOWN, DAVIS); female, SOUTH AFRICA: Cape Prov., Rooiheuwell (R. H. Watmough, PRETORIA-NC), female, ZIMBABWE: Bulawayo, VIII-5-23 (R. Stevenson, CAPE TOWN).

DISCUSSION: Among the few known South African cerastes group species in which both male F-I and F-II are shorter than III (Fig. 14), stevensoni is distinguished by its blue to purple color, small size, weak TFC and faintly impressed scrobal sulcus. The species is named for R. Stevenson, who collected many Zimbabwan chrysidids.

\section{Chrysis tesserops Bohart, new species}

HOLOTYPE MALE: Length $6.5 \mathrm{~mm}$. Body medium slender, bluegreen with ocellar triangle and midscutum partly purple, F-I-II green in front, III-X reddish brown, tarsi light brown, wings nearly clear. Punctation moderately coarse, a little spaced. F-I twice as long as broad (Fig. 15), II $1.2 \times$ and in some views faintly shorter than III; scapal basin finely punctate in outer two-fifths, mostly polished in middle one-fifth; TFC prominent, recurved, spectaclelike, enclosed "eyes" punctate but brightly reflective (Fig. 15). Malar space 1.2 MOD (ocellus small); subantennal space 1.6 MOD. Pronotum shorter than scutellum, median groove well marked; metanotum rounded; mesopleuron edentate, scrobal and episternal sulci shallow but distinct; propodeal projection pointed, nearly straight behind. No T-II midline; T-III evenly curved before pit row, lateral margin straight, pit row hardly indented but pits distinct, 4 sharp distal teeth, outer pair obtuse, inner pair acute, median notch deeper than submedian (Fig. 15); S-II spots large, long oval, narrowly separated. 
FEMALE: About as in male. F-I 2.3X as long as broad, III-X dark; tarsi brown; T-III saddled and with a low prepit convexity, pit row moderately deep.

Male holotype (GENOA), ETHIOPIA: Sagan-Omo, Cashel, VII8-39, (M. E. Zavattari). Paratypes, female, ZAIRE: Parc national Garamba (H. De Saeger, TERVUREN); female, TANZANIA: East Usambara, Amani, II-3-77 (O. Lomholdt, COPENHAGEN); female, SOUTH AFRICA: Transvaal Prov., Acornhoek, XI-1918 (R. W. Tucker, DAVIS).

DISCUSSION: Although male F-II is only marginally shorter than F-III, other features indicate that tesserops is in the splendidulasenegalensis group. The outstanding feature of tesserops is the spectacle-like form of TFC (Fig. 15). This formation has been observed in other unrelated Chrysis, but nowhere so extreme. In other respects there is a resemblance to senegalensis Mocsáry, but that species has the scapal basin microridged medially.

\section{Chrysis ugandae Bohart, new species}

HOLOTYPE MALE: Length $4.5 \mathrm{~mm}$. Body unusually slender, green to blue, notum and T-I-II apex with a faint coppery sheen, F-I green in front, wings nearly clear. Punctation moderate, slightly spaced, more so on scutum, intervals microsculptured. F-I 2.3X as long as broad; scapal basin finely punctate, narrowly polished medially (Fig. 16). TFC absent on broadly rounded brow, lateral acellus 1 MOD from eye, postocellar area unusually long; malar space 4 MOD, subantennal 1.3 MOD. Pronotum one-third longer than scutellum, median groove weak but present; metanotum rounded; mesopleuron edentate, episternal groove present, scrobal sulcus quite faint; propodeal projection short, pointed, slightly concave behind. T-II twice as long as T-III, midline evanescent; T-III evenly convex before pit row, lateral margin straight but concave near apex, pit row weakly impressed but pits relatively large, 4 distal teeth acute, sharp (Fig. 16) arranged in a rooflike curve; S-II spots large, long quadrate, narrowly separated.

FEMALE: About as in male. Length 5-6 mm. T-III median pair of teeth somewhat flaring, median emargination broader and shallower than lateral one.

Male holotype (BUDAPEST), UGANDA: Katona, Sept. 1913 (Mujenje coll.). Paratypes, 4 females, same data as holotype 
(BUDAPEST, DAVIS); paratype female, ZAIRE: Parc National Garamba, III-2-50 (H. DeSaeger, TERVUREN).

DISCUSSION: This species clearly belongs to the maindroni group, and is closely related to maindroni Buysson. Both have the very slender body, moderately long male F-I, long malar space, rounded brow without a TFC, long postocular area, obsolete scrobal sulcus, sharp T-III teeth, and large S-II spots. However, in ugandae the middle of the scapal basin is polished instead of microridged (Fig. 16), and the outer pair of T-III teeth are not unusually large. In longigena Mocsáry, also related, the interpunctural areas of the scutum are not extensively microsculptured and the lateral ocellus is 2 MOD from the eye.

\section{Chrysis whiteheadi Bohart, new species}

HOLOTYPE FEMALE: Length $7 \mathrm{~mm}$. Body moderately slender, greenish blue, grading to purple on vertex, midsection of scutum, terga except laterally and postpit area of T-III; F-I dark blue, wings lightly brownish. Punctation of head and thorax moderate and close, tergal punctures about a puncture diameter apart and intervening spaces microreticulate. F-I $3 \times$ as long as broad, scapal basin punctate in outer one-third, transversely microridged in depressed median one-third, TFC broadly M-like above extensive punctate area, fine posterior rami nearly enclosing midocellus; malar space 3.1 MOD; subantennal space 1.4 MOD; pronotum shorter than scutellum, median groove well developed; metanotum rounded; mesopleuron edentate, scrobal and episternal sulci distinct; propodeal projection sharp, incurved behind. No T-II midline; T-III saddled but with low prepit swelling, pit row not deep but pits distinct and a little longer than broad, distal rim evenly and broadly rounded; S-II spots moderately large, almost coalescent.

Female holotype (CAPE TOWN), SOUTH AFRICA: Cape Prov., Jonkershoek, near Stellenbosch, XII-27-70 (V. Whitehead). Paratype female, same data as holotype (DAVIS); paratype female, SOUTH AFRICA: Cape Prov., Hilton, XII-5-79 (F. W. and S. K. Gess, GRAHAMSTOWN).

DISCussion: The rounded distal rim of T-III, microreticulate interspaces between moderately large punctures on T-III, long malar space, and M-like TFC characterize the species. The T-III shape is similar to that in capitalis Dahlhom but in other respects 
whiteheadi is close to exsecata Mocsáry. The species is named for the collector of the holotype, my friend Vince Whitehead.

SUMMARY

Seventeen species of African Chrysis are described as new. Pertinent structural features are illustrated. Assignment to species groups has been made, when possible. New species are: Chrysis aspredinis, brothersi, capana, capicola, crenula, evexa, genosa, kenyana, krugerana, namibica, rhinata, senegalana, somaliae, stangei, stevensoni, tesserops, ugandae, and whiteheadi. 

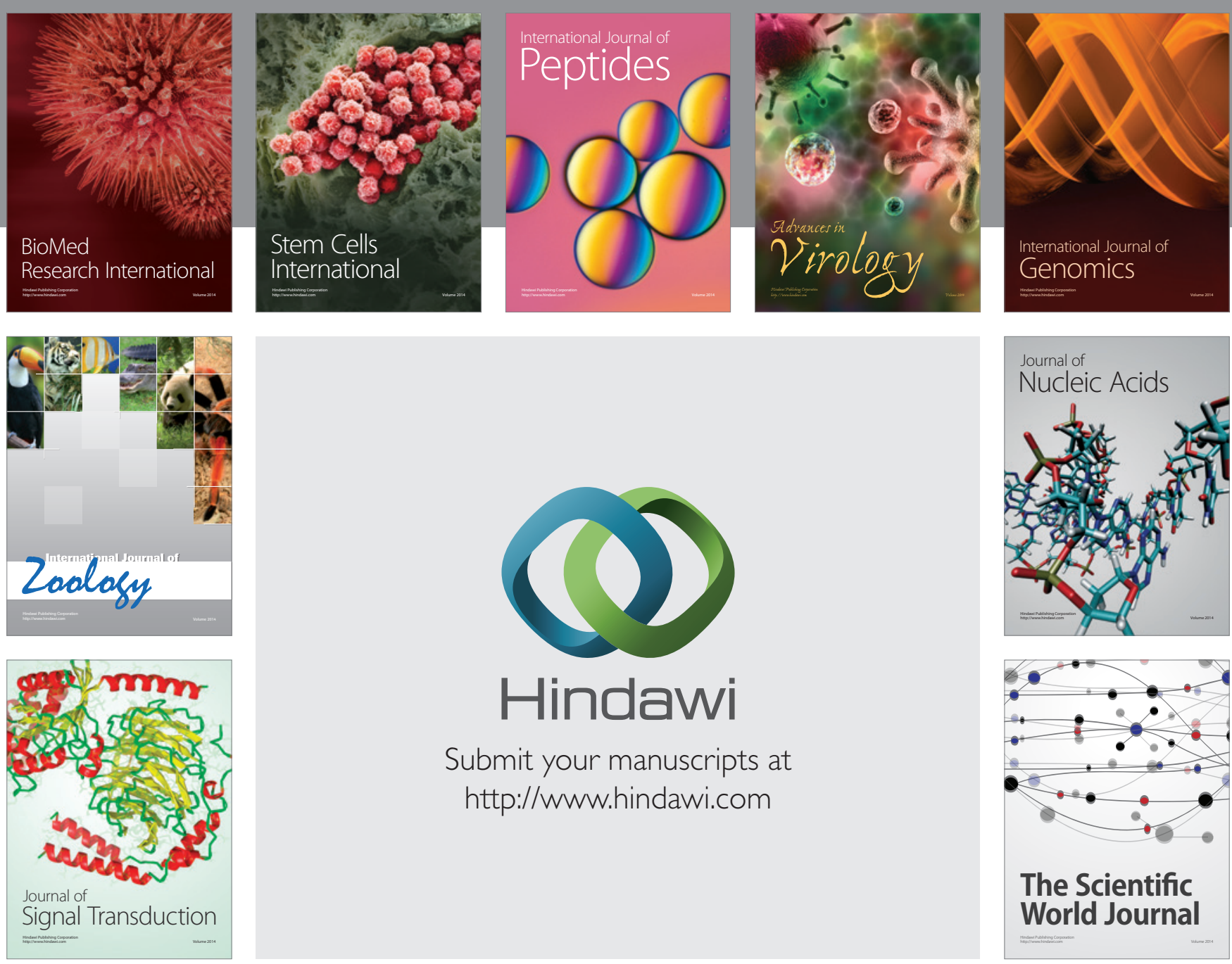

Submit your manuscripts at

http://www.hindawi.com
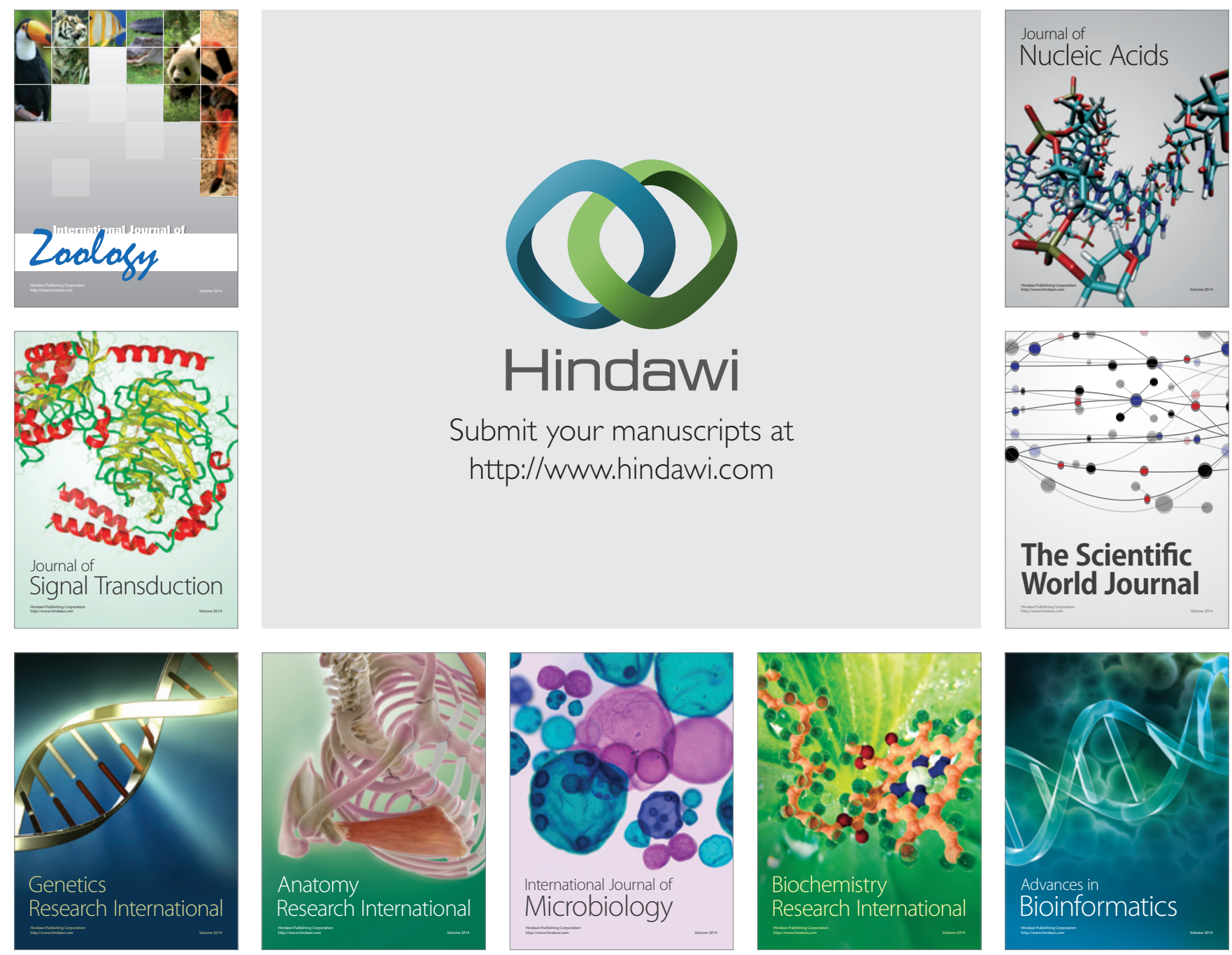

The Scientific World Journal
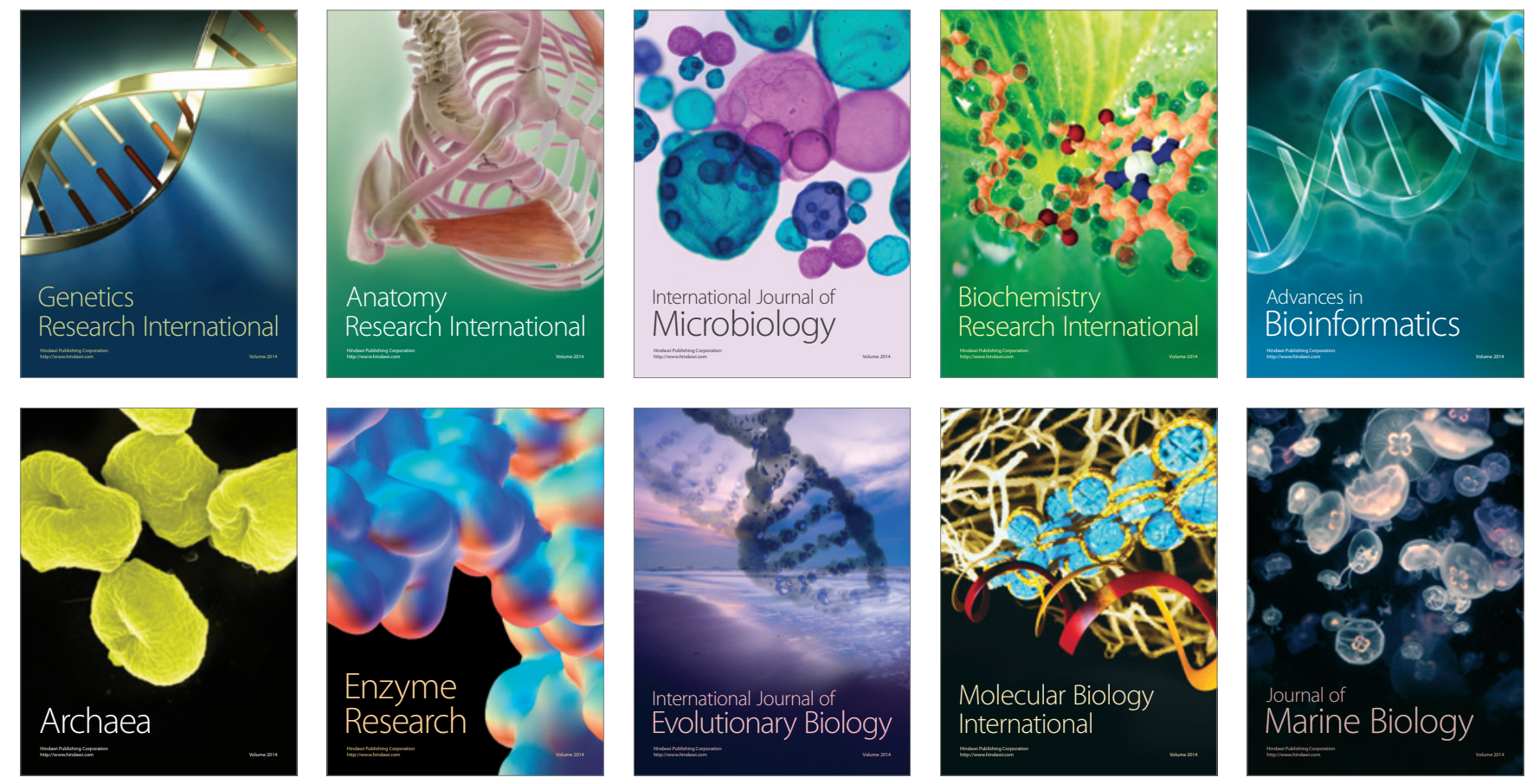